\section{Dilma e Aécio nos portais de Veja e CartaCapital em 2014: uma comparação entre editorias jornalísticas e blogs na cobertura das eleições presidenciais}

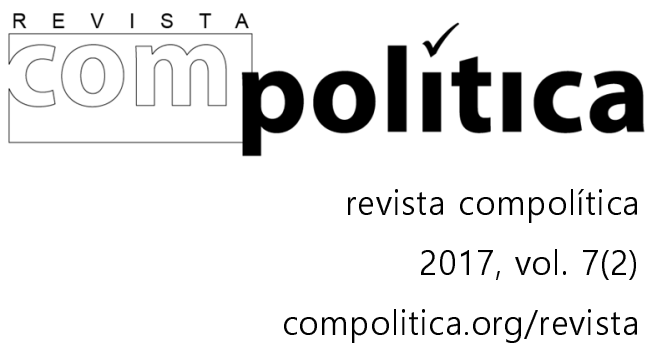

ISSN: 2236-4781

[Dilma and Aecio in the portals of Veja and CartaCapital in 2014: a comparative analysis between journalistic content and of weblogs in the coverage of the Brazilian presidential elections]
DOI: 10.21878/compolitica.2017.7.2.320 () Open Access Journal

\author{
Fernanda Cavassana de Carvalho \\ Universidade Federal do Paraná \\ Universidade Tecnológica Federal do Paraná \\ [Federal University of Paraná \\ Federal University of Technology - Paraná]
}

\title{
Resumo
}

Este artigo analisa a cobertura eleitoral on-line das revistas Veja e CartaCapital na disputa presidencial de 2014, identificando as diferenças entre o conteúdo veiculado por editorias jornalísticas daquele presente nos blogs de seus portais. A metodologia é a análise quantitativa de conteúdo, aplicada junto ao método comparativo, tomando-se como unidade de análise $o$ texto que cita pelo menos um dos dois principais candidatos: Dilma Rousseff e Aécio Neves. O corpus se constitui de 4258 textos veiculados durante o período de campanha - de 01 de julho a 26 de outubro de 2014 -, totalizando 3852 publicações de Veja e 406 de CartaCapital, tanto em reportagens jornalísticas quanto em postagens em blogs oficiais dos dois portais. $A$ hipótese de que os blogs geraram efeitos na cobertura on-line dessas revistas é confirmada $e$ evidenciada, principalmente, na valência negativa da cobertura de Veja à candidata Dilma Rousseff.

Palavras-chave: Mídia e Eleições, Cobertura Eleitoral, Eleições 2014.

\begin{abstract}
This article analyzes the online coverage of the Brazilian elections by two national magazines: Veja and CartaCapital. The analysis shows the differences between the journalistic content and the official blog's content in these magazines websites. The methodology is the quantitative content analysis with a comparative approach, and the unit analyzed is any text that mentioned at least one of the two main candidates: Dilma Rousseff and Aécio Neves. So the empirical corpus contains 4258 texts - posted between July 1st and October 26th 2014 -, 3852 of them from Veja's and 406 from CartaCapital's journalistic websites and official blogs. The hypothesis that blogs generate effects in the online electoral coverage of these magazines is confirmed and evidenced, mainly, in the negative treatment of the candidate Dilma Rousseff in Veja's coverage.
\end{abstract}

Keywords: Media and Elections, Electoral Coverage, Brazilian elections 2014. 


\section{Dilma e Aécio nos portais de Veja e CartaCapital em 2014: uma comparação entre editorias jornalísticas e blogs na cobertura das eleições presidenciais}

internet ganha cada vez mais destaque enquanto ambiente de circulação de
informações políticas. Contudo, grande parte desse conjunto de informações
ainda é oriunda de veículos tradicionais da imprensa, que hoje também atuam online. Os portais de notícia, que integram grandes grupos de comunicação do país, por exemplo, configuram-se como as páginas mais acessadas pelos brasileiros na web, ao lado dos sites de redes sociais (Brasil, 2014, p. 56). Além disso, há a difusão do conteúdo proveniente da imprensa em outros ambientes on-line, o que faz com que as pessoas também se informem por meio do conteúdo exposto em suas redes de relacionamento digitais.

Considerando essa conjuntura, este artigo $^{1}$ analisa a cobertura da disputa presidencial de 2014 pelas revistas Veja e CartaCapital na internet, comparando os conteúdos veiculados nas editorias jornalísticas e nos blogs de seus respectivos portais ${ }^{2}$. Aqui, destacam-se as revistas informativas semanais, que são veículos tradicionais da imprensa política brasileira que passaram a atuar no ambiente digital.

Nesse contexto, se antes só era possível ter acesso às coberturas eleitorais das revistas Veja e CartaCapital por meio da edição impressa semanal, ao longo da última disputa presidencial de 2014 os dois veículos também produziram constantemente notícias e outras publicações para seus portais na web, sem periodicidade definida. Assim, passaram a agregar características da produção on-line aos seus textos, além de explorar novos formatos e seções, como a de blogs e a veiculação de postagens de autoria externa à

\footnotetext{
${ }^{1}$ Resultado de pesquisa de dissertação desenvolvida no Programa de Pós-graduação em Comunicação da Universidade Federal do Paraná, com bolsa CAPES.

${ }^{2}$ Disponíveis em www.veja.abril.com.br e em www.cartacapital.com.br. Ressalta-se que a coleta dos dados foi realizado no segundo semestre de 2014, portanto, todas as características e seções dos dois portais citadas no artigo consideram a formatação dos websites naquele período.
} 
redação. Neste trabalho, os blogs de Veja e CartaCapital assumem lugar de destaque pelo número de publicações somadas ao longo da campanha e pela própria quantidade de blogs que cada portal possui.

As revistas Veja e CartaCapital são escolhidas como objeto de estudo porque apresentam engajamento político, especialmente nas disputas eleitorais, já evidenciado em pesquisas anteriores (Belmonte, 2011; Brogio, 2011; Cunha, 2010; Silva, 2011), como também em seus próprios editoriais. Esses dois veículos jornalísticos representam, ainda, ideologias e posicionamentos opostos (Carvalho, 2011; Gomes, 2007), o que deve ser levado em consideração, uma vez que as particularidades editoriais das empresas jornalísticas tendem a influenciar suas respectivas coberturas eleitorais. Justifica-se a análise de ambos os veículos na internet porque a circulação da revista impressa é essencialmente restrita, limitada a seus assinantes, consumidores irregulares e às poucas pessoas que têm contato com os exemplares em locais públicos, em oposição ao amplo acesso ao conteúdo on-line. Ambos os portais, inclusive, indicam elevada interatividade dos leitores com os conteúdos publicados, como o compartilhamento de suas publicações em outros ambientes on-line, como nas redes sociais.

Em relação ao tema pesquisado, considera-se a importância das eleições presidenciais, enquanto processo democrático de disputa, tanto pelo interesse de participação de uma parcela significativa da população quanto pelos esforços institucionais em tornar todo o processo acessível ao conhecimento público (Rubim, 2001; Gomes, 2011). Assim, não só mobiliza toda a imprensa e a opinião pública no período, como fornece um abrangente material para pesquisadores sobre o tema.

A partir disso, o objetivo deste artigo é identificar as diferenças entre o conteúdo eleitoral veiculado por editorias jornalísticas daquele presente nos blogs dos portais de CartaCapital e Veja, especialmente no que diz respeito às valências das publicações aos principais candidatos à Presidência da República em 2014. A pergunta que orienta a análise é: qual o efeito direto do conteúdo dos blogs na cobertura eleitoral on-line dessas revistas? A hipótese a ser testada é que o conteúdo dos blogs apresenta distinções significativas do conteúdo de editorias jornalísticas, uma vez que, no caso das revistas brasileiras, os colunistas e blogueiros têm maior liberdade para a produção de conteúdo, inclusive para se 
posicionarem textualmente a favor ou contra os candidatos. Assim, espera-se encontrar distinções por origem, inclusive, no que diz respeito às valências das publicações aos candidatos, ainda que se considere que os blogueiros tendem a representar o mesmo espectro ideológico e a defender o posicionamento político e editorial dos veículos em que atuam.

Para isso, faz-se uma comparação dos conteúdos veiculados em editorias jornalísticas e em blogs nos portais de CartaCapital e Veja durante o período eleitoral, uma vez que ambos os portais distinguem os conteúdos e páginas de seus websites por essas seções. A metodologia utilizada é comparativa, por meio da análise de conteúdo (Bauer, 2013) qualiquantitativa.

A partir dessa introdução, o artigo se divide em cinco partes. Primeiramente, são discutidas as inovações aplicadas às revistas brasileiras, tendo como fundo temático a cobertura de disputas presidenciais. Depois, discorre-se sobre o uso dos blogs como espaços específicos de publicações de conteúdo nos portais jornalísticos, incluindo o papel desempenhado por eles em coberturas eleitorais. Após a discussão teórica, são explicados os procedimentos metodológicos adotados, seguidos da análise empírica. Por fim, são apresentadas notas conclusivas, discutindo os resultados.

\section{As revistas nacionais e as disputas presidenciais no Brasil}

Os temas pautados pela imprensa durante a campanha, os enquadramentos e tratamentos dispensados aos candidatos e às suas propostas são exemplos de abordagens que despertam o interesse de pesquisas, especificamente, sobre a cobertura de veículos jornalísticos em períodos eleitorais. São trabalhos dedicados a verificar como o jornalismo contribui para o debate público durante as eleições. A influência do jornalismo na opinião pública ganha destaque no período porque "é no momento do voto ou das tomadas de posição a respeito de temas públicos que a opinião dos cidadãos comuns se cristaliza, indicando tendências e resultados do debate público" (Cervi, 2010, p. 11). 
$\mathrm{Na}$ literatura específica sobre o tema no Brasil, é possível encontrar diversas abordagens empíricas, como pesquisas voltadas para a imprensa local em eleições municipais (Aldé e Marques, 2015); a cobertura realizada pelos telejornais (Neves, 2009); pelos jornais impressos de circulação regional e nacional (Aldé; Mendes; Figueiredo, 2007; Cervi, 2012); como também pelas revistas semanais de informação (Jakobsen, 2007), segmento de atuação de Veja e CartaCapital, cujas publicações on-line são analisadas aqui. Atualmente, verifica-se uma tendência de estudos voltados para a cobertura jornalística eleitoral na internet, tanto em portais noticiosos (Massuchin; Cervi, 2013) quanto em blogs (Malini, 2007; Garavello, 2009) e redes sociais digitais, como o Twitter e o Facebook (Zago; Bastos, 2013; Mitozo; Massuchin; Carvalho, 2017).

Representando um dos segmentos da imprensa brasileira, as revistas semanais têm qualidades próprias que as diferem dos jornais diários impressos, para além de características técnicas e intrínsecas à produção textual, como formato, tamanho, cores, linguagem, uso de imagens e diagramação. Como particularidades, as revistas apresentam alta identificação e fidelidade de seu público leitor (Scalzo, 2013) e notícias e reportagens mais aprofundadas, investigativas e interpretativas (Vilas Boas, 1996), inclusive por apresentarem uma periodicidade maior em comparação ao jornalismo diário. Ainda que se considere na literatura o jornalismo de revista de interpretativo a opinativo (Azevedo, 2006; Vilas Boas, 1996), as revistas aqui analisadas pregam, em seus documentos institucionais e códigos de ética, a imparcialidade na cobertura jornalística. Há, pois, a autodefesa de que suas preferências políticas não interfiram na redação durante o processo da produção das notícias.

Seguindo o modelo iniciado pela norte-americana "Time", as revistas CartaCapital e Veja são consideradas semanais e informativas (Scalzo, 2013), produzindo e veiculando, principalmente, as chamadas hardnews. Segundo a classificação de Tuchman (1978), as notícias hard são voltadas ao cotidiano, pautadas pelos últimos acontecimentos, nacionais e mundiais, tratando de temas mais relevantes para o interesse público, como política e economia. Em contraste, as softnews são notícias com temas sem relevância social, com 
formatos mais livres e conteúdos voltados para o entretenimento, predominantes na maioria das revistas impressas brasileiras, classificadas como "não informativas"3.

Em relação às coberturas eleitorais, a revista Veja costuma realizar coberturas políticas críticas, tendo acirrado essa postura durante os últimos quatro governos petistas (20022016). É comum, por exemplo, a grande visibilidade dada a escândalos políticos que envolvam pessoas ligadas ao Partido dos Trabalhadores (PT) nas capas da revista da editora Abril. Esse estilo de cobertura jornalística fez com que a Veja se tornasse objeto de diversos estudos acadêmicos em diferentes áreas, como a Comunicação, Ciência Política e Linguística, principalmente sobre como a revista tem veiculado seu conteúdo e discurso na cobertura de temas polêmicos e de disputas eleitorais. As pesquisas sobre a atuação de Veja nas coberturas de eleições presidenciais demonstram que a revista não age imparcialmente, sendo possível identificar, em suas reportagens, análises e juízos de valor não só em defesa do candidato em disputa que representa seus interesses, como também contrários os candidatos que não partilham dos mesmos ideais do veículo (Belmonte, 2011; Brogio, 2011; Carvalho, 2011; Cunha, 2010; Gomes, 2007; Silva, 2011).

Durante as eleições de 2014, período de análise considerado nesse trabalho, Veja deu ênfase à “Operação Lava-jato”, escândalo envolvendo a denúncia de corrupção dentro da Petrobras durante os governos petistas. A recorrência de presença de denúncias e escândalos contra os candidatos nas capas da Veja durante campanhas eleitorais também já está registrado na literatura (Rubim, 2007; Colling, 2006).

Enquanto Veja costuma assumir uma cobertura de oposição, CartaCapital tendeu a ser governista durante os últimos oito governos eleitos. Por mais que defenda em seus códigos editoriais a prática de um jornalismo crítico e fiscalizador do poder, por pelo menos catorze anos, CartaCapital compartilhou e defendeu os mesmos interesses do Governo Federal, representado pelo Partido dos Trabalhadores (PT) e pelos presidentes Luiz Inácio Lula da Silva e Dilma Rousseff. Segundo seu fundador e diretor de redação Mino Carta, a revista tem defendido os interesses da nação e, portanto, também das empresas nacionais e

\footnotetext{
${ }^{3}$ As duas concorrentes analisadas aqui também veiculam softnews. Destaca-se, porém, a existência de notícias hards em Veja e CartaCapital porque isso faz com que elas contribuam com o debate público e eleitoral, diferentemente da grande maioria das revistas impressas brasileiras, focada no entretenimento. Outros dois exemplos de revistas de informação no Brasil são IstoÉ e Época.
} 
multinacionais que trabalham em proveito do país (PAULINO, 2002). Nas disputas presidenciais, o veículo tem declarado publicamente seu posicionamento, assinando editoriais favoráveis aos candidatos do PT desde 2002.

Como candidata à reeleição, Dilma teve o apoio público de CartaCapital anunciado pelo editorial veiculado no dia 04 de julho de 2014, um dia antes do início oficial da campanha. Nesse editorial ${ }^{4}$, o veículo também tratou sobre os demais candidatos, opositores ao governo, afirmando respeitá-los, mas que eles já teriam o apoio de outros meios e que estariam "destinados inexoravelmente a representar, mesmo à sua própria revelia, a pior direita, a reação na sua acepção mais trágica" (Carta, 2014). Com isso, CartaCapital tornou explícita não só a sua preferência política e ideológica, mas sua aversão aos veículos concorrentes, como Veja.

\section{Os blogs na cobertura eleitoral das revistas em 2014}

A existência dos blogs vinculados aos portais noticiosos tornou-se comum aos veículos de imprensa na web. Entre as diferenças principais da produção de conteúdo de um blog para as editorias de notícias, mesmo nos portais, está a de "não limitação". O blogueiro domina o espaço, o tamanho da publicação, bem como o direcionamento do seu texto, sem se impor às rotinas produtivas do jornalismo impostas à redação. Mesmo que o conteúdo e a autoria sejam diferentes dos textos veiculados pela redação, são considerados blogs jornalísticos por comporem os portais dos veículos tradicionais. Nesses sites, os blogs são destinado a publicações , como uma aposta das empresas no na produção individual de conteúdo e no interesse do público (Quadros; Rosa; Vieira, 2005), assemelhando-se às colunas e aos artigos do impresso (Primo, 2008), uma vez que se configuram espaços para textos de opinião de seus autores.

É interessante frisar que, apesar de representarem uma oportunidade para a produção de conteúdo alternativa à mídia convencional, os blogs que possuem maior número de visitas

\footnotetext{
${ }^{4}$ Disponível em http://www.cartacapital.com.br/revista/807/por-que-escolhemos-dilma-rousseff-131.html. Acesso em setembro de 2014.
} 
e difusão de seu conteúdo são os vinculados aos portais jornalísticos. O conteúdo político eleitoral oriundo de blogs, por exemplo, só ganha destaque quando estes já estão vinculados a grupos tradicionais de comunicação (Garavello, 2009). Isso tanto porque fazem parte de grupos midiáticos mais bem estruturados de recursos tecnológicos, financeiros e até de pessoas - o que garante maior circulação do conteúdo - quanto porque os blogs acabam adquirindo parte do conhecimento e da credibilidade que as empresas jornalísticas tradicionais já construíram e possuem.

Segundo Primo (2008), o blog vinculado a um veículo de imprensa pode ser considerado como do gênero "blog profissional reflexivo", em que o administrador da página (o blogueiro) se destina a opinar e fazer críticas a determinado tema. $\mathrm{O}$ autor também descreve que os blogs profissionais são escritos por uma pessoa com especialização em determinada área, não importando se possui formação nela. Neste caso, "cada texto carrega um valor qualitativo prévio em virtude da atuação passada do especialista, ao mesmo tempo em que oferece repercussão no valor futuro dos próximos posts e na própria reputação do autor" (Primo, 2008).

Os blogs políticos acabam oferecendo materiais importantes para pesquisas empíricas na área de comunicação, especialmente pelos conteúdos veiculados nesses espaços. Alguns trabalhos já apontaram a diferença do conteúdo veiculado por não jornalistas a partir de blogs e, inclusive, sua influência na cobertura eleitoral de portais jornalísticos (Garavello, 2009). Nas eleições de 2006, por exemplo, o conteúdo eleitoral originado em blogs dominou o debate no período da disputa presidencial especialmente sobre os dois principais candidatos (Malini, 2007). E há também os blogs políticos mais próximos da disputa que podem ser analisados a partir de suas coberturas em eleições locais, como foi feito em Curitiba na campanha de 2008 (Cervi e Vieira, 2009).

Os blogueiros e colunistas de CartaCapital e Veja ganham destaque nos portais pela liberdade que possuem na produção de seus posts, tanto em relação ao conteúdo quanto na quantidade de material publicado. São figuras públicas, conhecidas nacionalmente pelo seu engajamento político ou pela atuação enquanto jornalistas. São formadores de opinião. Uma característica encontrada nas publicações desses blogs é a replicação de textos dos próprios portais da revista, acrescidos de comentários e interpretações dos blogueiros. Tal 
comportamento já havia sido evidenciado na pesquisa de Malini (2007), na qual, ao tratar na opinião pública em ambiente on-line, identificou a importância desses líderes de opinião na rede ao indicarem temas, links e publicações, direcionando os internautas entre tantas possíveis fontes de informação na rede.

Assim, os blogs também informam e atuam na construção e no enquadramento da realidade para seu público. Ainda que tenham liberdade para produzir e veicular opiniões sobre os mais diversos temas, suas publicações somam-se ao noticiário informativo do veículo e passam a complementar o jornalismo político exercido pela imprensa na internet. Também contribuem, portanto, por meio da informação, interpretação ou opinião, com o debate público, especialmente evidenciado no período eleitoral.

Considera-se, portanto, que a autonomia relativa do público não só em produzir conteúdos alternativos na internet, mas também em selecionar as notícias que irá ler, não exclui totalmente o papel do jornalismo político em despertar o interesse do webleitor para determinadas publicações a serem utilizadas no debate público. Aldé (2011), por exemplo, mostra que os portais noticiosos tendem a ser referência para assuntos políticos, e suas notícias sobre candidatos são as mais lembradas pelos eleitores que utilizam a internet. A falta de controle sobre a produção de conteúdo na web pode ser, inclusive, um dos motivos que incentiva o consumo do conteúdo dos veículos tradicionais mesmo na web, bem como de seus blogs, uma vez que tendem a ser mais confiáveis aos leitores.

\section{Metodologia}

Para responder a pergunta na qual se baseia esta análise - qual o efeito direto do conteúdo dos blogs na cobertura eleitoral on-line dessas revistas? -, opta-se por uma metodologia comparativa de análise de conteúdo. A estratégia comparativa possibilita formular as proposições necessárias para responder a pergunta, por permitir identificar as semelhanças e as particularidades do conteúdo dos blogs em contraste com o que foi veiculado nas editorias jornalísticas, seções presentes nos dois portais, aqui contempladas na variável "origem". Para constituição do corpus empírico, que totalizou 4258 textos, foram 
selecionadas todas as publicações textuais ${ }^{5}$ dos portais de Veja (3852) e CartaCapital (406) que mencionavam pelo menos um dos dois principais candidatos à presidência: Aécio Neves e Dilma Rousseff ${ }^{6}$. Como recorte temporal, é considerado todo o período de campanha eleitoral, desde o dia 01 de julho de 2014 ao dia 26 de outubro de 2014, data em que se encerrou o segundo turno.

Para análise do conteúdo dessas publicações foram criadas variáveis do tipo categórica, "que mede a distribuição das quantidades de qualidades das características estudadas e cujos valores que dão sentido às qualidades são arbitrados pelo pesquisador" (Cervi, 2014, p.8). Para que seja possível quantificar a frequência de determinada qualidade na análise de conteúdo, ela tem que ser codificada, exigindo a leitura e interpretação em cada unidade de análise (Bauer, 2013), o texto dos portais que cita ao menos um dos candidatos, neste caso. Para tanto, utiliza-se um livro de códigos previamente elaborado ${ }^{7}$, que restringe as classificações das variáveis, dialogando com o referencial teórico. Aqui, são consideradas as variáveis origem, formato, fonte, tema, valência a Aécio Neves e valência a Dilma Rousseff, cujas categorias são explicadas a seguir.

A primeira variável codificada é de origem do texto dentro do portal, que identifica se ele é oriundo de editorias jornalísticas ou da seção de blogs. Por sua vez, a variável fonte identifica os tipos de atores ou instituições que apareceram como fontes de informação para as publicações. Foram consideradas como categorias de fonte: a) política (ator político e/ou líder partidário); b) figura pública (figura conhecida publicamente, mas sem vínculo político partidário e sem conhecimento especializado sobre o assunto); c) especialista (especialista no tema da publicação, detentor de conhecimento, que apresenta comentários técnicos sobre o tema); d) cidadão individual (eleitores leigos, não representantes de instituições); e) imprensa (outros veículos de imprensa); f) pesquisas (institutos de pesquisa, como IBGE, Datafolha e Ibope, ou até mesmo universidades). Como não há

\footnotetext{
${ }^{5}$ A unidade de análise de conteúdo aqui se restringe ao texto escrito. Desconsidera-se, portanto, publicações que faziam referências aos candidatos apenas por meio de imagens (foto, vídeo, charge, etc.).

${ }^{6}$ A coleta se deu por meio de buscas avançadas, ao longo da campanha, textualmente pelos nomes dos candidatos nos próprios portais das duas revistas. Assim, outros termos que faziam referências a Aécio Neves (como por exemplo: senador, candidato do PSDB, ex-governador de Minas) e a Dilma Rousseff (presidente, presidenta, petista, candidata à reeleição) não foram considerados para a seleção dos textos.

${ }^{7}$ Tendo como principal aporte a metodologia e as variáveis do Grupo de Pesquisa em Comunicação Política e Opinião Pública (CPOP), da Universidade Federal do Paraná (UFPR) - www.cpop.ufpr.br, onde os autores atuam como pesquisadores.
} 
regras para as publicações, especialmente para os blogs, nem todo texto tem fonte mencionada. Assim, há a possibilidade dessa variável ser ausente nos casos analisados.

Já a variável tema procura identificar o assunto abordado na publicação. É importante reforçar que este trabalho não parte da análise dos textos que tratavam especificamente da campanha eleitoral à Presidência, mas sim de todas as publicações que citavam ao menos um dos três candidatos, estes podendo ter sido mencionados em textos sobre os mais diversos temas. Assim, foram definidas como categorias temáticas: a) eleição presidencial (especificamente sobre a disputa); b) político-institucional (partidos, governos, instituições e campanhas de outras esferas); c) cotidiano (temas de interesse cotidiano dos eleitores, como saúde, desemprego, educação, transporte e inflação); d) economia (macroeconomia); e) minorias (programas sociais, manifestações e/ou demandas de minorias); f) ético-moral (denúncias, corrupção, temas morais); g) internacional (relações internacionais); h) outro (quando não se enquadrar nas anteriores).

Sobre a valência ao candidato, é possível mensurar o tratamento dado a cada presidenciável na publicação. Ressalta-se, aqui, que a interpretação dessa variável não diz respeito à qualidade do texto, não interpreta se o mesmo é neutro ou possui valores, tampouco julga se o conteúdo influenciará a percepção do leitor sobre cada candidato. Essa variável se relaciona diretamente com a construção da imagem do candidato ao longo da cobertura eleitoral dos dois veículos, mensurando se a publicação o aborda de maneira positiva ou negativa, ou se não o apresenta sob nenhum destaque (neutra).

Para a valência positiva ao candidato, foram estipuladas como regras de codificação: textos que relatam ações de iniciativa do candidato; declarações - de ordem moral, política ou pessoal - favoráveis ao candidato e/ou às suas propostas de governo; textos que ressaltam ações ou citações propostas do candidato sobre algum tema específico; e quando houver divulgação de resultados de pesquisas ou estudos favoráveis ao candidato. Com valência negativa, foram considerados textos com ressalvas, críticas ou ataques ao candidato e/ou às suas propostas; textos que traziam denúncias - como as de corrupção - envolvendo o candidato e seu partido, inclusive ressaltando evidências contra eles; e também quando houver divulgação de resultados de pesquisas ou estudos desfavoráveis à candidatura. A valência ao candidato será neutra quando não houver avaliação moral, política ou pessoal 
sobre o candidato ou quando houver, no texto, a evidência de aspectos positivos e negativos ao candidato, compreendendo que há neutralização da polarização da imagem do candidato. Geralmente, são textos que apenas relatam a agenda de campanha ou quando há a mera citação do candidato sem dar relevância ao mesmo.

Uma mesma publicação, por exemplo, pode trazer aspectos positivos da campanha de Dilma e criticar as propostas de Aécio, ou vice-versa ou, ainda, somente descrever o compromisso agendado pelos candidatos naquele dia, sem tecer comentários positivos e/ou negativos a cada um deles. Por isso, há uma variável de valência para cada candidato, preenchida somente se ele for citado no texto e respeitando estritamente a descrição que é imposta a cada categoria da variável.

Após a leitura, interpretação e codificação das unidades textuais, o banco de dados construído é analisado de forma quantitativa, por meio de testes estatísticos específicos e análise de dados categóricos. No caso deste artigo, opta-se por testes que possibilitam a comparação direta entre corpus de diferentes tamanhos - considerando que a quantidade de publicações de Veja é dez vezes superior à de CartaCapital ${ }^{8}$. Sendo origem a nossa variável independente aqui, os testes verificam se há associação da mesma com as demais variáveis de conteúdo. Considerando todos os aspectos detalhados aqui, apresenta-se a análise empírica na sequência.

\section{Análise empírica - Comparações na cobertura eleitoral on-line das revistas por origem}

A primeira análise a ser feita explicita a quantidade de publicações por origem nos portais, conforme a tabela 1 , que indica as primeiras diferenças entre as duas revistas. Nota-se que Veja publicou textos sobre os candidatos quase dez vezes mais que CartaCapital. É importante lembrar que Veja integra um grupo de comunicação maior que a concorrente,

\footnotetext{
${ }^{8}$ Como é o caso do teste de resíduos padronizados. Também se utiliza o teste do qui-quadrado para verificar se a distribuição nas categorias comparadas são equilibradas ou se há concentração de determinada característica, indicando associação entre as variáveis cruzadas. Bem como o teste $\mathrm{V}$ de Cramer, que mensura a magnitude da associação quando identificada.
} 
apresentando maiores recursos, inclusive humanos, já que possui uma redação maior que a de CartaCapital, o que influencia nessa comparação. Contudo, destaca-se também a diferença em relação às publicações de blogs e editorias. A cobertura eleitoral de CartaCapital foi altamente concentrada nas notícias, enquanto Veja concentrou, comparativamente, mais textos de blogs, como indicam os resíduos padronizados (RP). Enquanto para cada 10 textos de CartaCapital um era de blog e nove de editoria jornalística; em Veja a cada três textos, dois eram de blog e um de editoria jornalística. Ou seja, os posts de blogueiros de Veja totalizaram o dobro das notícias do portal na campanha eleitoral.

\section{Tabela 1 - Volume de textos por origem e revista}

\begin{tabular}{l|l|l|l|l}
\hline \multicolumn{2}{l|}{} & Editoria jorn. & Blog & Total \\
\hline \multirow{3}{*}{ CartaCapital } & $\mathrm{n}$ & 368 & 38 & 406 \\
\cline { 2 - 5 } & $\%$ & 90,6 & 9,4 & 100 \\
\cline { 2 - 5 } & $\mathrm{RP}$ & 16,6 & $-13,3$ & \\
\hline \multirow{3}{*}{ Veja } & $\mathrm{n}$ & 1299 & 2553 & 3852 \\
\cline { 2 - 5 } & $\%$ & 33,7 & 66,3 & 100 \\
\cline { 2 - 5 } & $\mathrm{RP}$ & $-5,4$ & 4,3 & \\
\hline Total & $\mathrm{n}$ & 1667 & 2591 & 4258 \\
\hline
\end{tabular}

Fonte: $A$ autora.

Já a tabela 2, abaixo, compara a presença textual dos candidatos nas duas revistas por origem. Os dados permitem dizer que, apesar das diferenças indicadas na tabela 1 sobre a produção de conteúdo eleitoral entre as seções nas duas revistas, não há grandes diferenças quando se comparam os dois candidatos. As proporções identificadas na tabela anterior entre blog e editoria - se mantêm nas duas revistas. Há uma quantidade maior de textos que citam Dilma em comparação a Aécio em todos os casos, mas isso já era esperado nesta análise, considerando que, além de candidata, Dilma era a Presidente da República no período, portanto, tendia a aparecer em mais textos, não apenas naqueles que tratavam das eleições. 
Tabela 2 - Textos que citam candidatos por revista e origem

\begin{tabular}{l|l|l|l|l|l}
\hline \multicolumn{2}{c}{} & \multicolumn{2}{c|}{$\begin{array}{l}\text { Editoria } \\
\text { jorn. }\end{array}$} & Blog & Total \\
\hline \multirow{4}{*}{ CartaCapital } & \multirow{2}{*}{ Cita Dilma } & $\mathrm{n}$ & 330 & 36 & 366 \\
\cline { 3 - 6 } & & $\%$ & 90,2 & 9,8 & 100 \\
\cline { 3 - 6 } & \multirow{2}{*}{ Cita Aécio } & $\mathrm{n}$ & 248 & 20 & 268 \\
\cline { 3 - 6 } & & $\%$ & 92,5 & 7,5 & 100 \\
\hline \multirow{4}{*}{ Veja } & \multirow{2}{*}{ Cita Dilma } & $\mathrm{n}$ & 1178 & 2302 & 3480 \\
\cline { 3 - 6 } & & $\%$ & 33,9 & 66,1 & 100 \\
\cline { 2 - 6 } & \multirow{2}{*}{ Cita Aécio } & $\mathrm{n}$ & 753 & 1186 & 1939 \\
\cline { 3 - 6 } & & $\%$ & 38,8 & 61,2 & 100 \\
\hline
\end{tabular}

As informações da tabela 2 são relevantes aqui porque permitem refutar ressalvas em relação à concentração ou ausência de presença de um dos candidatos em cada seção, para cada portal. Assim, as demais comparações sobre o conteúdo eleitoral entre blog e editoria podem ser feitas, especialmente quando se considerar a valência à cada candidato. Tais comparações passam a ser o foco da análise a partir daqui. A intenção é verificar o que há de similar e o que há de particular entre os textos por origem nas duas revistas, testando a hipótese levantada.

Primeiramente, são descritos os coeficientes estatísticos para o cruzamento de origem com as demais variáveis em CartaCapital. A tabela 3 indica algumas associações estatisticamente significativas. Os dados demonstram que a origem do texto em CartaCapital gera modificações na cobertura eleitoral on-line da revista somente no que diz respeito ao tema da publicação. A associação é maior entre origem e tema $(37,4 \%)$, conforme o coeficiente V de Cramer. 
Tabela 3 - Associação de origem com cada variável categórica em CartaCapital

\begin{tabular}{l|l|l|l}
\hline Variável & $x^{2}$ & Sig. & Cramer's V \\
\hline Tema & 56,693 & 0,000 & 0,374 \\
\hline Fonte & 8,894 & 0,180 & 0,148 \\
\hline Valência à Dilma & 1,314 & 0,518 & 0,060 \\
\hline Valência a Aécio & 0,168 & 0,919 & 0,025 \\
\hline
\end{tabular}

Fonte: $A$ autora.

Ainda da tabela 3, destaca-se que as valências dos textos aos dois candidatos não sofrem alterações a partir da origem da publicação. Tanto para Dilma Rousseff quanto para Aécio Neves, não há associação significativa. Isso quer dizer que independentemente do local de publicação, blog ou editoria jornalística, a construção da imagem de Dilma e Aécio se deram de modo semelhante no portal da CartaCapital. Por outro lado, a revista Veja indica associações significativas da variável origem com as valências à cada um dos candidatos, conforme a tabela 4 abaixo. Especialmente a valência à Dilma se modifica conforme a origem do texto, como indica os coeficientes abaixo.

Tabela 4 - Associação de origem com cada variável categórica em Veja

\begin{tabular}{l|r|r|r}
\hline Variável & \multicolumn{1}{|c|}{$x^{2}$} & \multicolumn{1}{c|}{ Sig. } & Cramer's V \\
\hline Tema & 31,264 & 0,000 & 0,090 \\
\hline Fonte & 411,617 & 0,000 & 0,327 \\
\hline Valência à Dilma & 211,725 & 0,000 & 0,247 \\
\hline Valência a Aécio & 13,393 & 0,001 & 0,084 \\
\hline
\end{tabular}

Fonte: $A$ autora.

Além disso, no caso da revista Veja, a tabela 4 indica que há associações significativas da variável origem com todas as variáveis consideradas aqui. Isso significa dizer que, em Veja, os textos produzidos para os blogs diferenciam-se bastante daqueles veiculados nas editorias jornalísticas do portal. Enquanto CartaCapital indica maior associação com tema, em Veja destaca-se a relação de origem com fonte nas publicações, que apresenta, comparativamente, uma associação de maior magnitude $(32,7 \%)$. Na sequência, a valência à Dilma em Veja por origem também é reforçada $(24,7 \%)$. Os dados, no entanto, ainda não 
suficientes para detalhar em quais categorias das duas variáveis há concentração ou ausência dessas características, o que é investigado no próximo tópico.

\section{Particularidades por origem na cobertura eleitoral on-line das revistas em 2014}

Avançando a análise de comparação entre o conteúdo publicado em editorias jornalísticas e blogs de CartaCapital, a tabela 5 indica as primeiras particularidades dos textos dos blogs da revista no que diz respeito ao tema, cuja associação significativa com origem foi constatada anteriormente. Verifica-se que houve predomínio da eleição presidencial como tema predominante nos textos tanto de editorias jornalísticas $(50,3 \%)$, seguido de políticoinstitucional $(16,6 \%)$ e ético-moral $(10,1 \%)$. Contudo, na comparação direta com blogs, não há ausência ou concentração significativa de nenhuma temática para as editorias. Por outro lado, comparativamente aos demais temas e origem, os resíduos padronizados indicam uma ausência significativa do tema eleição presidencial nos blogs de CartaCapital $(-2,4)$. 
Tabela 5 - Tema por origem em CartaCapital

\begin{tabular}{|c|c|c|c|c|c|c|c|c|c|c|}
\hline & & 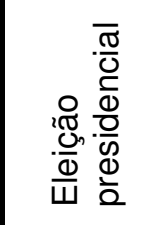 & 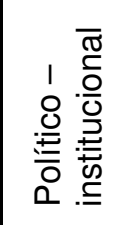 & $\begin{array}{l}0 \\
\frac{0}{0} \\
\frac{\pi}{0} \\
\frac{0}{0} \\
0 \\
0\end{array}$ & 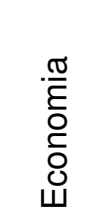 & 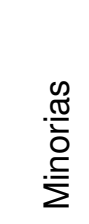 & 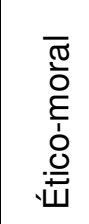 & 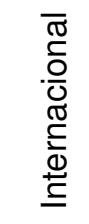 & 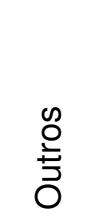 & $\begin{array}{l}\bar{\pi} \\
\stackrel{0}{0}\end{array}$ \\
\hline \multirow{3}{*}{$\begin{array}{l}\text { Editoria } \\
\text { jornalística }\end{array}$} & $n$ & 185 & 61 & 16 & 27 & 16 & 37 & 12 & 14 & 368 \\
\hline & $\%$ & 50,3 & 16,6 & 4,3 & 7,3 & 4,3 & 10,1 & 3,3 & 3,8 & 100 \\
\hline & $\begin{array}{l}\mathrm{R} \\
\mathrm{P}\end{array}$ & 0,8 & $-0,1$ & 0,4 & 0,5 & $-1,6$ & 0,3 & $-0,9$ & $-1,0$ & \\
\hline \multirow{3}{*}{ Blog } & $n$ & 8 & 7 & 0 & 0 & 10 & 2 & 5 & 6 & 38 \\
\hline & $\%$ & 21,1 & 18,4 & 0,0 & 0,0 & 26,3 & 5,3 & 13,2 & 15,8 & 100 \\
\hline & $\begin{array}{l}\mathrm{R} \\
\mathrm{P}\end{array}$ & $-2,4$ & 0,3 & $-1,2$ & $-1,6$ & 4,9 & $-0,9$ & 2,7 & 3,0 & \\
\hline \multirow{2}{*}{ Total } & $n$ & 193 & 68 & 16 & 27 & 26 & 39 & 17 & 20 & 406 \\
\hline & $\%$ & 47,5 & 16,7 & 3,9 & 6,7 & 6,4 & 9,6 & 4,2 & 4,9 & 100 \\
\hline
\end{tabular}

Fontes: $A$ autora.

Nota-se que a associação entre as variáveis também é consequência da alta concentração de determinadas temáticas em blogs. Há concentração significativa, acima do que se era esperado, para os temas: minorias $(4,9)$, internacional $(2,7)$ e outros $(3)$ - categoria esta que pode abranger cultura, meio ambiente ou esportes, por exemplo. A pluralidade de temas dos posts nos blogs de CartaCapital foi a principal diferença destes com os textos jornalísticos da revista, uma vez que, nas editorias, os candidatos eram citados, principalmente, em publicações sobre a cobertura eleitoral ou sobre a política institucional. 
Tabela 6 - Tema por origem em Veja

\begin{tabular}{|c|c|c|c|c|c|c|c|c|c|c|}
\hline & & 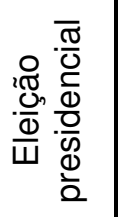 & 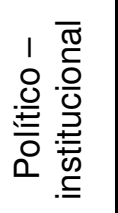 & 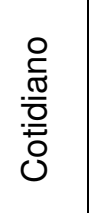 & 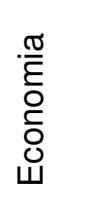 & 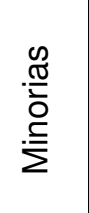 & 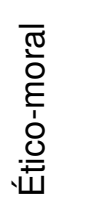 & 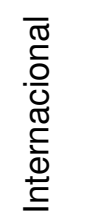 & 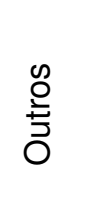 & 氶 \\
\hline \multirow{3}{*}{$\begin{array}{l}\text { Editoria } \\
\text { jornalística }\end{array}$} & $\mathrm{n}$ & 563 & 223 & 82 & 166 & 22 & 162 & 24 & 57 & 1299 \\
\hline & $\%$ & 43,3 & 17,2 & 6,3 & 12,8 & 1,7 & 12,5 & 1,8 & 4,4 & 100 \\
\hline & $\begin{array}{l}\mathrm{R} \\
\mathrm{P}\end{array}$ & $-0,6$ & $-1,8$ & 1,3 & 3,2 & $-0,1$ & 0,8 & $-1,8$ & $-0,3$ & \\
\hline \multirow{3}{*}{ Blog } & $n$ & 1149 & 524 & 129 & 219 & 44 & 290 & 78 & 120 & 2553 \\
\hline & $\%$ & 45,0 & 20,5 & 5,1 & 8,6 & 1,7 & 11,4 & 3,1 & 4,7 & 100 \\
\hline & $\begin{array}{l}\mathrm{R} \\
\mathrm{P}\end{array}$ & 0,4 & 1,3 & $-0,9$ & $-2,3$ & 0,0 & $-0,6$ & 1,3 & 0,2 & \\
\hline \multirow{2}{*}{ Total } & $n$ & 1712 & 747 & 211 & 385 & 66 & 452 & 102 & 177 & 3852 \\
\hline & $\%$ & 44,4 & 19,4 & 5,5 & 10,0 & 1,7 & 11,7 & 2,6 & 4,6 & 100 \\
\hline
\end{tabular}

Fonte: $A$ autora.

Outra associação moderada encontrada com a variável origem diz respeito às fontes mencionadas nas publicações de Veja. Sobre isso, a tabela 7 caracteriza como se dá essa relação, evidenciando diferenças significativas entre textos jornalísticos e blogs de Veja. Primeiramente, evidencia-se a ausência da fonte mencionada nos blogs, recurso não utilizado em $50,2 \%$ dos textos, com resíduo significativo positivo $(7,8)$. 


\section{Tabela 7 - Fonte por origem em Veja}

\begin{tabular}{|c|c|c|c|c|c|c|c|c|c|}
\hline & & 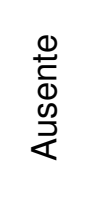 & $\begin{array}{l}\stackrel{\mathscr{J}}{\stackrel{\Xi}{0}} \\
0\end{array}$ & 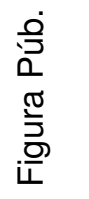 & 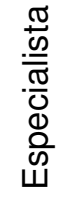 & 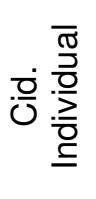 & 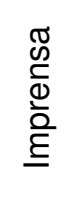 & $\begin{array}{l}\mathbb{0} \\
. \frac{0}{\bar{T}} \\
\bar{O} \\
0 \\
0 \\
0\end{array}$ & $\begin{array}{l}\bar{\pi} \\
\stackrel{0}{0}\end{array}$ \\
\hline \multirow{3}{*}{$\begin{array}{l}\text { Editoria } \\
\text { jornalística }\end{array}$} & $n$ & 263 & 624 & 116 & 88 & 35 & 76 & 97 & $\begin{array}{r}129 \\
9\end{array}$ \\
\hline & $\%$ & 20,2 & 48 & 8,9 & 6,8 & 2,7 & 5,9 & 7,5 & 100 \\
\hline & $\begin{array}{l}\mathrm{R} \\
\mathrm{P}\end{array}$ & $10, \overline{9}$ & 9,1 & 4,9 & 5 & 1 & $4, \overline{1}$ & 2 & \\
\hline \multirow{3}{*}{ Blog } & $\mathrm{n}$ & 1245 & 662 & 104 & 66 & 53 & 285 & 138 & $\begin{array}{r}255 \\
3\end{array}$ \\
\hline & $\%$ & 48,8 & 25,9 & 4,1 & 2,6 & 2,1 & $\begin{array}{r}11, \\
2\end{array}$ & 5,4 & 100 \\
\hline & $\begin{array}{l}\mathrm{R} \\
\mathrm{P}\end{array}$ & 7,8 & $-6,5$ & $-3,5$ & $-3,6$ & $-0,7$ & 3 & $-1,4$ & \\
\hline \multirow[t]{2}{*}{ Total } & $\mathrm{n}$ & 1508 & $\begin{array}{r}128 \\
6 \\
\end{array}$ & 220 & 154 & 88 & 361 & 235 & $\begin{array}{r}385 \\
2 \\
\end{array}$ \\
\hline & $\%$ & 39,1 & 33,4 & 5,7 & 4 & 2,3 & 9,4 & 6,1 & 100 \\
\hline
\end{tabular}

Fonte: A autora.

Na mesma perspectiva, há ausência dos demais tipos de fonte para os textos dos blogs e concentração positiva, e significativa, conforme os resíduos, entre a editoria e fontes política $(9,1)$; figura pública $(4,9)$; especialistas (5); e institutos de pesquisa (2). Para os blogs, o resíduo padronizado significativo positivamente se dá para o uso da imprensa como fonte (3), característica recorrente em 11,2\% das publicações. Citar outros veículos para embasar suas análises, especialmente sobre política e economia, fora ação comum aos blogueiros de Veja.

De forma geral, até aqui, a análise considerou apenas as associações moderadas entre as variáveis analisadas nas duas revistas. Para averiguar e descrever se houve efeito direto dos blogs no tratamento dado aos candidatos na cobertura eleitoral, analisa-se, agora, independente da força de associação mensurada anteriormente, o cruzamento entre origem e as variáveis de valência para cada candidato em cada revista. 


\section{Valências aos candidatos por origem na cobertura de 2014}

A tabela 3 indicou que não há associação estatisticamente significativa entre origem e as variáveis de valência, nem a Dilma Rousseff, nem a Aécio Neves na CartaCapital. Sobre isso, a tabela 8, a seguir, traz detalhes da relação entre as categorias dessas variáveis para a revista que se posicionou editorialmente a favor da candidata à reeleição.

No caso do tratamento aos dois candidatos, pode-se comparar as colunas de origem com as valências e se observar que há uma distribuição semelhante entre as categorias tanto para blogs, quanto para editorias jornalísticas. Todos os resíduos padronizados se aproximam de zero, indicando que não há ausência e presença acima da esperada. Assim, constata-se que, no portal de CartaCapital, as críticas e os elogios aos dois candidatos estão distribuídos de modo semelhante entre postagens em blogs e em editorias jornalísticas.

\section{Tabela 8 - Valências por origem em CartaCapital}

\begin{tabular}{|c|c|c|c|c|c|c|c|}
\hline & & \multicolumn{3}{|c|}{ Valência a Dilma } & \multicolumn{3}{|c|}{ Valência a Aécio } \\
\hline & & Editoria & Blog & Total & Editoria & Blog & Total \\
\hline \multirow{3}{*}{ Positiva } & $\mathrm{n}$ & 134 & 15 & 149 & 54 & 4 & 58 \\
\hline & $\%$ & 40,6 & 41,7 & 40,7 & 21,8 & 20 & 21,6 \\
\hline & $\mathrm{RP}$ & 0,0 & 0,1 & & 0,0 & $-0,2$ & \\
\hline \multirow{3}{*}{ Negativa } & $\mathrm{n}$ & 61 & 4 & 65 & 100 & 9 & 109 \\
\hline & $\%$ & 18,5 & 11,1 & 17,8 & 40,3 & 45 & 40,7 \\
\hline & $\mathrm{RP}$ & 0,3 & -0.9 & & $-0,1$ & 0,3 & \\
\hline \multirow{3}{*}{ Neutra } & $\mathrm{n}$ & 135 & 17 & 152 & 94 & 7 & 101 \\
\hline & $\%$ & 40,9 & 47,2 & 41,5 & 37,9 & 35 & 37,7 \\
\hline & $\mathrm{RP}$ & $-0,2$ & 0,5 & & 0,1 & $-0,2$ & \\
\hline \multirow{2}{*}{ Total } & $\mathrm{n}$ & 330 & 36 & 366 & 248 & 20 & 268 \\
\hline & $\%$ & 100 & 100 & 100 & 100 & 100 & 100 \\
\hline & & \multicolumn{3}{|c|}{$x^{2}=1,314 \mid$ Sig.: 0,518 } & \multicolumn{3}{|c|}{$x^{2}=0,168 \mid$ Sig.: 0,919 } \\
\hline
\end{tabular}

Fonte: $A$ autora.

Descartada a interpretação de que os blogs alteram a valência das publicações aos candidatos no caso de CartaCapital, a informação que a tabela 8 nos dá é a comparação direta entre as valências dos dois candidatos na cobertura em geral da revista. Nota-se, por exemplo, que nas vezes em que foi citada textualmente a imagem de Dilma foi positiva em 
40,7\% das publicações, sendo que em 41,5\% a valência é neutra e em 17,8\% a candidata aparece de modo negativo em CartaCapital. Por outro lado, Aécio Neves teve valência negativa em 40,7\% dos textos que o citavam, $37,7 \%$ de valência neutra e apenas $21,6 \%$ positiva. Dados esperados pelo posicionamento da revista. Já na tabela 9, abaixo, é detalhada a distribuição aos candidatos nas publicações de Veja conforme a origem do texto no portal. Todos os cruzamentos são estatisticamente significativos, conforme os resíduos padronizados em evidência.

\section{Tabela 9 - Valências por origem em Veja}

\begin{tabular}{l|l|r|r|r|r|r|r}
\hline \multicolumn{2}{c|}{} & \multicolumn{3}{c|}{ Valência a Dilma } & \multicolumn{3}{c}{ Valência a Aécio } \\
\cline { 3 - 9 } \multicolumn{2}{c|}{} & Editoria & Blog & Total & Editoria & Blog & Total \\
\hline \multirow{3}{*}{ Positiva } & $\mathrm{n}$ & 285 & 219 & 504 & 373 & 567 & 940 \\
\cline { 2 - 8 } & $\%$ & 24,2 & 9,5 & 14,5 & 49,5 & 47,8 & 48,5 \\
\cline { 2 - 8 } & $\mathrm{RP}$ & $\mathbf{8 , 8}$ & $-\mathbf{6 , 3}$ & & $\mathbf{0 , 4}$ & $\mathbf{- 0 , 3}$ & \\
\hline \multirow{3}{*}{ Negativa } & $\mathrm{n}$ & 413 & 1333 & 1746 & 98 & 101 & 199 \\
\cline { 2 - 9 } & $\%$ & 35,1 & 57,9 & 50,2 & 13,0 & 8,5 & 10,3 \\
\cline { 2 - 8 } & $\mathrm{RP}$ & $\mathbf{- 7 , 3}$ & $\mathbf{5 , 2}$ & & $\mathbf{2 , 4}$ & $\mathbf{- 1 , 9}$ & \\
\hline \multirow{3}{*}{ Neutra } & $\mathrm{n}$ & 480 & 750 & 1230 & 282 & 518 & 800 \\
\cline { 2 - 8 } & $\%$ & 40,7 & 32,6 & 35,3 & 37,5 & 43,7 & 41,3 \\
\cline { 2 - 8 } & $\mathrm{RP}$ & $\mathbf{3 , 1}$ & $\mathbf{- 2 , 2}$ & & $-\mathbf{1 , 6}$ & $\mathbf{1 , 3}$ & \\
\hline \multirow{2}{*}{ Total } & $\mathrm{n}$ & 1178 & 2302 & 3480 & 753 & 1186 & 1939 \\
\cline { 2 - 8 } & $\%$ & 100 & 100 & 100 & 100 & 100 & 100 \\
\hline & & $\mathrm{x}^{2}=211,725$ & Sig.: & 0,000 & $\mathrm{x}^{2}=13,393$ & Sig.: 0,001 \\
\hline
\end{tabular}

Fonte: $A$ autora.

Destaca-se que a valência negativa de Dilma em Veja é recorrente em $35,1 \%$ dos textos das editorias jornalísticas, mas está presente em 57,9\% dos textos dos blogs da revista, o que gerou um resíduo positivo $(5,2)$. Em contrapartida, há resíduo positivo $(8,8)$ para a valência positiva à Dilma em editorias jornalísticas $(24,2 \%)$ e de $-6,3$ para a mesma valência nas postagens de blogueiros, as quais abordaram positivamente a candidata à reeleição em apenas 9,5\% das vezes que a citaram. Assim, a alta concentração da imagem negativa de Dilma em Veja aparece como uma consequência também da alta produção de matérias em blogs da revista, que se dá, inclusive, em maior intensidade ao longo do tempo.

Do mesmo modo, a valência negativa a Aécio em Veja é evidenciada como ausente, abaixo do esperado na comparação com todas as categorias, presente nas postagens que tem os 
blogs como origem $(-1,9)$ e significativamente acima do esperado nas publicações jornalísticas $(2,4)$. Especialmente no primeiro turno, as valências negativas em publicações jornalísticas eram recorrentes em textos que analisavam o desempenho do candidato tucano na disputa eleitoral. Aécio Neves cresceu na campanha próximo à decisão, sendo que ao longo do primeiro turno chegou a representar a terceira candidatura da disputa. A valência negativa ao candidato, independentemente da origem, é pouco recorrente. Contudo, os resíduos se dão, em suma, pela quase inexistência desta característica nos textos dos blogs.

\section{Conclusões}

Destaca-se, neste trabalho, como o uso da cobertura on-line altera a dinâmica e a relação das tradicionais revistas semanais impressa com as disputas políticas e eleitorais, especialmente pela presença dos blogs em seus portais. A convergência tecnológica e a atuação em ambientes digitais permitem a veículos convencionalmente impressos ultrapassar alguns limites no que tange à produção, como a periodicidade e a publicação de conteúdos sem a citação de fontes, por exemplo. Contudo, a escolha editorial por portais que comportam diferentes formatos de textos, desde grandes reportagens aos posts de blogueiros, gera alterações diretas no conteúdo ofertado por essas revistas, aqui ilustrado pelo período de campanha política.

Por mais que diversos trabalhos já tenham identificado a tendência à uma cobertura negativa de Veja e à uma cobertura positiva de CartaCapital aos candidatos dos Partidos dos Trabalhadores ao longo do histórico das disputas presidenciais; tem-se neste trabalho uma indicação do elevado caráter interpretativo e opinativo na cobertura de 2014. É evidente que espaços destinados a conteúdo opinativo e informativo existem nos veículos independentemente da plataforma em que se veicula seu conteúdo. No entanto, algumas mudanças no tratamento aos candidatos tornam-se salientes com a elevada produção de conteúdo político e eleitoral nesses blogs.

A hipótese de que os blogs geraram efeitos na cobertura on-line dessas revistas foi confirmada, sendo identificados alguns níveis diferentes desse efeito nas duas revistas e 
em alguns aspectos do conteúdo. A análise empírica permite afirmar que a principal mudança na cobertura das eleições na comparação entre as duas revistas ocorre em Veja, especialmente no que diz respeito às valências à Dilma. Nela, o conteúdo eleitoral sofre mais alterações com as publicações dos blogueiros que, ainda, é bastante superior às publicações jornalísticas. Em Veja, os blogs publicaram o dobro de textos que as editorias no portal.

Assim, se por um lado é possível afirmar que os blogs de Veja fizeram com que a cobertura de seu portal noticioso fosse essencialmente negativo à candidata Dilma Rousseff; por outro lado, é possível identificar a escolha editorial de reforçar o conteúdo informativo sobre a disputa no site, uma vez que as editorias jornalísticas apresentaram em sua maioria conteúdo neutro em relação à Dilma, concentrando a maioria dos textos com essa característica em comparação aos blogs.

E essa diferenciação na cobertura eleitoral como consequência da atuação dos blogs também é evidenciado em CartaCapital. Por mais que os dados da revista não indiquem diferenças significativas no que diz respeito às valências aos candidatos entre conteúdo de blog e de editoria, foi identificada uma significativa concentração de temas sociais nos blogs do portal. Ou seja, uma indicação de que variação da origem do texto no portal que também afeta o conteúdo.

Outro aspecto a ser considerado é a ampliação dos efeitos dessa cobertura com a atuação dos blogs na produção de conteúdo, ainda que isso não seja mensurado aqui por não ser escopo do trabalho. Considerados líderes de opinião, muitos dos blogueiros desses dois portais possuem maior capacidade de influenciar o debate público, especialmente nos ambientes digitais.

Especialmente no que se refere à produção da informação e às novas configurações do jornalismo na era digital, assume-se aqui a importância de novos estudos abordarem a nova função dos produtos jornalísticos na rede, uma vez que os portais noticiosos tendem a ser referência para assuntos políticos e eleitorais, mas não possuem mais o controle de produção e difusão das informações políticas. É importante frisar que não se desconsidera o potencial da internet em permitir que conteúdos alternativos aos tradicionais sejam 
produzidos e circulados nas esferas digitais. Apenas ressalta-se a relevância de se observar e se considerar, especialmente, a produção de conteúdo on-line da imprensa convencional dada a importância, a força e a credibilidade de veículos tradicionais, como revistas e jornais impressos, que possuem uma atuação consolidada na cobertura de eleições presidenciais brasileiras.

\section{Referências}

ALDÉ, A.; MARQUES, F. P. Internet e poder local. Salvador: EDUFBA, 2015.

ALDÉ, A., MENDES, G., FIGUEIREDO, M. Tomando partido: imprensa e eleições presidenciais em 2006. Política \& Sociedade, n. 10, p.153-172, abr. 2007.

ALDÉ, A. O internauta casual: notas sobre a circulação da opinião pública na internet. Revista USP. São Paulo, n.90, p. 24-4, jun/ago 2011.

AZEVEDO, F. A. Democracia e Mídia no Brasil: Um balanço dos anos recentes. In: GOULART, J. A. (Org.). Mídia e Democracia. São Paulo: Annablume, 2006.

BAUER, Martin W. Análise de Conteúdo clássica: uma revisão. In: BAUER, Martin W.; GASKELL, George (orgs). Pesquisa qualitativa com texto, imagem e som: Um Manual prático. 11ํㅡㄹ ed. Petrópolis: Vozes, 2013.

BELMONTE, Wagner Barge. A cobertura da eleição presidencial de 2010 pela revista Veja. Dissertação (Mestrado em Comunicação). São Paulo: Faculdade Cásper Líbero, 2011.

BRASIL, Presidência da República. Secretaria de Comunicação Social. Pesquisa brasileira de mídia 2015: hábitos de consumo de mídia pela população brasileira. Brasília: Secom, 2014.

BROGIO, T. M. Marketing político e a reeleição de Fernando Henrique Cardoso: um estudo sobre a comunicação durante a campanha nas páginas da revista Veja em 1998. Dissertação (Mestrado em Ciências da Comunicação). São Bernardo do Campo: Universidade Metodista de São Paulo, 2011.

CARTA, Mino. Por que escolhemos Dilma Rousseff. CartaCapital. Editorial, 4 de julho de 2014. Disponível em: <http://www.cartacapital.com.br/revista/807/por-que-escolhemos-dilma-rousseff131.html>. Acesso: abr 2015.

CARVALHO, F. C. Observatório de Mídia: As eleições presidenciais de 2010 nas capas das revistas semanais. Trabalho de Conclusão de Curso (Graduação em Comunicação Social Habilitação Jornalismo). Londrina: Universidade Estadual de Londrina, 2011.

CERVI, E. U. Opinião pública e comportamento político. Curitiba: IBPEX, 2010.

CERVI, E. Quando Lasswell encontra a cobertura eleitoral da FSP. In: STRELOW, A. et al. (Orgs.). Jornalismo: histórias, teorias, gêneros e práticas. 1ed. São Paulo: Intercom, p. 453-487, 2012. 
CERVI, E. Análise de dados categóricos em Ciência Política. Curitiba: E-book PPGCP, 2014.

CERVI, E.; VIEIRA, S. A cobertura jornalística de blogs políticos nas eleições para a Prefeitura Municipal de Curitiba de 2008. SBPJor - Associação Brasileira de Pesquisadores em Jornalismo. VII Encontro Nacional de Pesquisadores em Jornalismo. São Paulo: USP, 2009.

COLLING, L. Os Estudos Sobre Mídia e Eleições Presidenciais no Brasil Pós-Ditadura. Tese (Doutorado em Comunicação). Salvador: Universidade Federal da Bahia, 2006.

CUNHA, J. V. Mídia e marketing político: a campanha eleitoral de Fernando Henrique Cardoso para presidente, nas páginas da revista Veja em 1994. Dissertação (Mestrado em Comunicação Social). São Bernardo do Campo: Universidade Metodista de São Paulo, 2010.

GARAVELLO, M. Os blogs e o jornalismo de texto: a campanha para a eleição presidencial de 2006 no Brasil. Dissertação (Mestrado em Ciências da Comunicação). São Paulo: Universidade de São Paulo, 2009.

GOMES, I. As três imagens de Lula: Os posicionamentos das revistas CartaCapital, Primeira Leitura e Veja nas eleições para presidente em 2002. Dissertação (Mestrado em Comunicação Social). São Bernardo do Campo: Universidade Metodista de São Paulo, 2007.

GOMES, W. Transformações da política na era de comunicação de massa. $3^{2}$ ed. São Paulo: Paulus, 2011.

JAKOBSEN, K. A. A cobertura da Mídia Impressa aos Candidatos nas Eleições Presidenciais de 2006. In: LIMA, V. (Org.). A mídia nas eleições de 2006. São Paulo: Editora Fundação Perseu Abramo, 2007.

MALINI, F. A opinião pública distribuída: blogs e jornalismo nas Eleições Brasileiras de 2006. Ecompós, p. 1-21, ago. 2007.

MASSUCHIN, M.; CERVI, E. Jornalismo político e interesse do público: as notícias mais lidas do dia e o papel dos portais como fonte de informação política em período eleitoral. In: ROCHA, D., PANKE, L., MACEDO, R. (Orgs). O Jornalismo político nos processos eleitorais. Capivari: Editora Nova Consciência, 2013.

MITOZO, I. B.; MASSUCHIN, M.; CARVALHO, F. C. Debate político-eleitoral no Facebook: os comentários do público em posts jornalísticos na eleição presidencial de 2014. Opinião Pública, v. 23, n. 2, 2017.

NEVES, F. Telejornalismo e Poder nas Eleições Presidenciais. São Paulo: Summus Editorial, 2009.

PRIMO, A. Blogs e seus gêneros: Avaliação estatística dos 50 blogs mais populares em língua portuguesa. XXXI Congresso Brasileiro de Ciências da Comunicação - Intercom. Natal. 2008.

QUADROS, C; ROSA, A. P; VIEIRA, J. Blogs e as transformações do jornalismo. E-compós, v.3, p. 2-21, 2005.

PAULINO, R. A. F. Mino, jornalista de opinião (Entrevista com Mino Carta). Comunicação \& Educação, n. 23, p. 71-90, 2002. 
RUBIM, A. A. C. Novas Configurações das Eleições na Idade Mídia. Opinião Pública. Campinas, Vol. VII, n.2, p. 168-181, 2001.

RUBIM, A. A. C. Ética da política e ética na política nas eleições de 2006. In: LIMA, Venício A. de. Lima (Org). A Mídia nas Eleições de 2006. São Paulo: Fundação Perseu Abramo, 2007.

SCALZO, M. Jornalismo de Revista. São Paulo: Contexto, 2013.

SILVA, J.C. R. da. Época, Veja e o (E)leitor: Estratégias discursivas na construção da imagem de presidenciáveis. Tese (Doutorado em Lingüística). Brasília: Universidade de Brasília, 2011.

TUCHMAN, G. Making News: a study in the construction of reality. Nova York: The Free Press, 1978.

VILAS BOAS, S. O Estilo Magazine. O Texto em Revista. São Paulo: Summus Editorial, 1996.

ZAGO, G.; BASTOS, M. Visibilidade de notícias no Twitter e no Facebook: Análise comparativa das notícias mais repercutidas na Europa e nas Américas. Revista USP, n.90, p. 24-41, 2013.

\section{A autora}

Fernanda Cavassana de Carvalho é doutoranda em Ciência Política na Universidade Federal do Paraná e professora substituta em Comunicação na Universidade Federal Tecnológica do Paraná. cavassanaf@gmail.com 